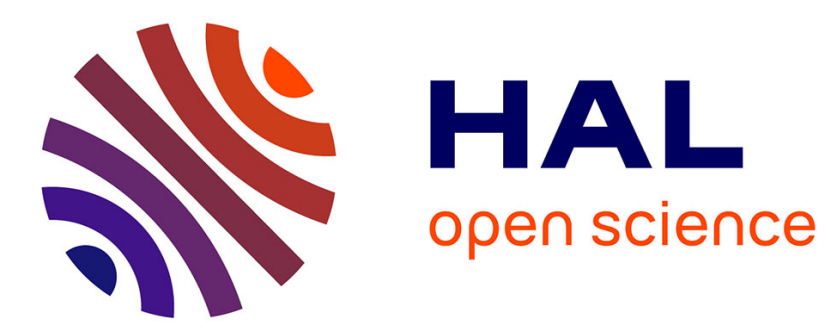

\title{
Comparing predicted and observed ground motions from subduction earthquakes in the Lesser Antilles
}

John Douglas, Rosemarie Mohais

\section{To cite this version:}

John Douglas, Rosemarie Mohais. Comparing predicted and observed ground motions from subduction earthquakes in the Lesser Antilles. Journal of Seismology, 2009, 13 (4), pp.577-587. 10.1007/s10950008-9150-y . hal-00557605

\section{HAL Id: hal-00557605 https: / hal-brgm.archives-ouvertes.fr/hal-00557605}

Submitted on 19 Jan 2011

HAL is a multi-disciplinary open access archive for the deposit and dissemination of scientific research documents, whether they are published or not. The documents may come from teaching and research institutions in France or abroad, or from public or private research centers.
L'archive ouverte pluridisciplinaire HAL, est destinée au dépôt et à la diffusion de documents scientifiques de niveau recherche, publiés ou non, émanant des établissements d'enseignement et de recherche français ou étrangers, des laboratoires publics ou privés. 


\title{
Comparing predicted and observed ground motions from subduction earthquakes in the Lesser Antilles
}

\author{
John Douglas ${ }^{1} \&$ Rosemarie Mohais ${ }^{2,3}$ \\ 1. BRGM - ARN/RIS, 3 avenue C. Guillemin, BP 36009, 45060 Orléans Cedex 2, France. \\ 2. Seismic Research Center, University of West Indies, St Augustine, Trinidad \& Tobago. \\ 3. Now at: University of South Australia, School of Mathematics and Statistics, \\ Mawson Lakes, 5095, South Australia, Australia.
}

November 14, 2008

\begin{abstract}
This brief article presents a quantitative analysis of the ability of eight published empirical ground-motion prediction equations (GMPEs) for subduction earthquakes (interface and intraslab) to estimate observed earthquake ground motions on the islands of the Lesser Antilles (specifically Guadeloupe, Martinique, Trinidad and Dominica). In total, over 300 records from 22 earthquakes from various seismic networks are used within the analysis. It is found that most of the GMPEs tested perform poorly, which is mainly due to a larger variability in the observed ground motions than predicted by the GMPEs, although two recent GMPEs derived using Japanese strong-motion data provide reasonably good predictions. Analyzing separately the interface and intraslab events does not significant modify the results. Therefore, it is concluded that seismic hazard assessments for this region should use a variety of GMPEs in order to capture this large epistemic uncertainty in earthquake ground-motion prediction for the Lesser Antilles.
\end{abstract}

\section{Introduction}

The large $\left(M_{w} 7.4\right)$ earthquake that occurred between the islands of Martinique and Dominica in the Lesser Antilles on 29th November 2007 demonstrated the importance of deep intraslab earthquakes in this subduction zone. This earthquake was widely felt throughout the eastern Caribbean and it caused damage to buildings on Martinique and Barbados and slight damage on other islands in the region, e.g. Dominica. On Martinique the macroseismic intensity was estimated to be between VI and VII on the EMS98 scale [Schlupp et al., 2008]. 
Due to the lack of sufficient strong-motion data recorded on islands of the Lesser Antilles seismic hazard assessments in this region are currently obliged to adopt or adapt published ground-motion prediction equations (GMPEs) derived using the much more abundant data from other subduction zones with longer histories of strong-motion observation (e.g. Japan, Cascadia, South America, Taiwan and New Zealand). However, in adopting such GMPEs the implicit assumption made is that they adequately predict the median ground motions and the ground-motion variability from earthquakes occurring in the Lesser Antilles.

In a previous article Douglas et al. [2006] examined the ability of various GMPEs to accurately predict shaking from crustal and subduction earthquakes recorded on the French Antilles (Guadeloupe and Martinique). They found that for crustal earthquakes none of the nine considered GMPEs closely predicted the observed ground motions nor their variabilities. However, this could be related to the application of the considered GMPEs outside their ranges of applicability since as demonstrated by, for example, Bommer et al. [2007] predictions from GMPEs can become unreliable for magnitudes and distances near and beyond the edges of the distribution of the dataset used to derive the models. For subduction earthquakes (both interface and intraslab) Douglas et al. [2006] considered three often-used models developed using data from subduction zones worldwide: Atkinson and Boore [2003], Crouse [1991] and Youngs et al. [1997], and found that the model of Youngs et al. [1997] predicts reasonably well earthquake ground motions recorded on the French Antilles but the other two models poorly predict such motions. The majority of the records used by Douglas et al. [2006] for subduction earthquakes were from interface events: 91 records from eleven interface earthquakes compared to 56 records from three intraslab earthquakes. Consequently the results obtained may better reflect the ability of the three examined models to estimate ground motions from interface events rather than intraslab earthquakes.

Given the importance of deep intraslab earthquakes in the Lesser Antilles, in this short article we extend the intraslab dataset used by Douglas et al. [2006] by the addition of six strong-motion records from the strong-motion network on the island of Trinidad to the south of Guadeloupe and Martinique and one record from a station on Dominica between Guadeloupe and Martinique. In addition, since the study of Douglas et al. [2006] was completed three other intraslab earthquakes have been well recorded by the extensive strong-motion networks on Guadeloupe and Martinique, including that of the 29th November 2007, and, therefore, these data have been included in the analysis. In total, the intraslab strong-motion dataset from the Lesser Antilles consists of 146 records from nine earthquakes. In addition, the interface strong-motion dataset of Douglas et al. [2006] is extended by the inclusion of 68 records from three interface events that occurred since the completion of the original study. Recently a 
number of robust GMPEs for subduction zones have been published and, therefore, in this article we examine the applicability of five new ground-motion models in addition to the three models originally tested.

\section{Data selected}

Douglas et al. [2006] present an overview of the strong-motion networks operating in the Caribbean and a detailed description of the strong-motion networks of Guadeloupe and Martinique. Therefore in this study we only give details of the accelerometric network on Trinidad, which consists of five stations, and one station on Dominica that was operational from 2003 to 2004 (see Table 1). Since the publication of Douglas et al. [2006] a few new stations have been added to the BRGM strong-motion networks on Guadeloupe and Martinique and a couple of instruments have been moved. For details of these modifications see the website of the Centre de Données Sismologiques des Antilles (CDSA, http://www.seismes-antilles.fr/) [Bengoubou-Valerius et al., 2008].

In agreement with Douglas et al. [2006] in this study only data from earthquakes in the Global Centroid Moment Tensor catalogue have been retained for analysis. This limits the study to the largest earthquakes (moment magnitude $M_{w} \gtrsim 5$ ) whose ground motions could be of engineering interest and also means that only earthquakes with consistently determined focal mechanisms and moment magnitudes are retained, thereby meaning magnitude conversions or approaches to unify the database are not required. Table 3 lists the strong-motion data from the nine intraslab and thirteen interface earthquakes within the Global CMT catalogue available from networks on Guadeloupe, Martinique, Trinidad and a single station on Dominica in 2003 and 2004. Events were classified as intraslab, interface or crustal (not considered in this article) based on their horizontal and vertical locations with respect to the subduction zone and their focal mechanisms. Interface earthquakes are produced at the interface of the subducting slab (to the east of the Lesser Antilles island arc) and generally have a reverse mechanism whereas intraslab earthquakes occur at depth within the subducting slab (approximately underneath the islands) and generally have a normal mechanism [e.g. Atkinson and Boore, 2003]. All the available strong-motion data was visually inspected and poor-quality records or records that were thought to have been misassigned to an earthquake were discarded. Figure 1 presents a map showing the locations and focal mechanisms of the selected earthquakes and the recording stations. Figure 2 displays the magnitude-distance-event type distribution of the selected data, showing that the majority of the available data is from moderate events $\left(M_{w}<6\right)$ and large hypocentral distances $\left(R_{\text {hypo }}>100 \mathrm{~km}\right)$. 
From the considered earthquakes and seismic networks two records were available from digital broadband velocity sensors (CMG-40Ts) of the Bouillante array operated by BRGM. These were corrected for instrument response and then converted to acceleration through timedomain differentiation. The rest of the available data were from modern digital accelerometers so instrument correction to obtain acceleration was not required. In addition, these data were of sufficient quality in the period range 0 to $2 \mathrm{~s}$ not to require band-pass filtering to obtain accurate spectral accelerations for these periods; hence, no filtering was applied. If velocity or displacement time-histories were of interest then high-pass filter would have been been necessary.

Some instruments in the Lesser Antilles are located in the ground floor of buildings rather than in instrument shelters (see our Table 1 and Table 1 of Douglas et al. [2006]). Therefore, soil-structure interaction (SSI) could affect the high frequencies of records from these stations, particularly if they are located on soft soil. However, most of the structures housing instruments are small (one or two-storey houses) and, thus, the effect of SSI on observed ground motions is likely to be negligible [e.g. Stewart, 2000] and it has not been considered here. 
Table 1: Information on strong-motion stations that have operated, or are still operating,

on Trinidad and Dominica and whose data has been used in this article. All these stations

belong to the Seismic Research Center (SRC) of the University of West Indies. R is rock

and $\mathrm{S}$ is soft soil (in this case reclaimed land).

\begin{tabular}{|c|c|c|c|c|c|c|c|c|c|c|}
\hline Name & Code & Island & $\begin{array}{l}\text { Lat. } \\
(\mathrm{N})\end{array}$ & $\begin{array}{l}\text { Long. } \\
\text { (W) }\end{array}$ & $\begin{array}{r}\text { Elev. } \\
(\mathrm{m})\end{array}$ & $\begin{array}{r}\text { Installed } \\
\text { DD/MM/YYYY }\end{array}$ & $\begin{array}{r}\text { Removed } \\
\text { DD/MM/YYYY }\end{array}$ & Site & Instrument & Location \\
\hline Brigand Hill & $\mathrm{TBH}$ & Trinidad & 10.4840 & 61.0670 & 199 & $11 / 06 / 2000$ & & $\mathrm{R}$ & $\mathrm{K} 2$ & Ground floor of concrete structure \\
\hline Chaguaramas & TCHG & Trinidad & 10.6800 & 61.6600 & 21 & $20 / 12 / 2001$ & & $\mathrm{R}$ & $\mathrm{K} 2$ & Ground floor of concrete building in military base \\
\hline Hallcrest & DHCT & Dominica & 15.5700 & 61.4200 & 4 & $05 / 05 / 2003$ & 07/03/2004 (stolen) & $\mathrm{R}$ & $\mathrm{K} 2$ & Ground floor of concrete house \\
\hline Point Cumana & TPTC & Trinidad & 10.6800 & 61.5700 & 49 & $21 / 09 / 2000$ & $19 / 12 / 2001$ & $\mathrm{R}$ & K2 & Ground floor of concrete house \\
\hline Point Fortin & ALNG & Trinidad & 10.1814 & 61.6883 & 0 & $25 / 01 / 2001$ & & $\mathrm{R}$ & $\mathrm{K} 2$ & Ground floor of small concrete shelter in natural gas processing plant \\
\hline West Moorings & TWMO & Trinidad & 10.6700 & 61.5600 & 0 & $21 / 09 / 2000$ & & $\mathrm{~s}$ & $\mathrm{~K} 2$ & Ground floor of concrete house \\
\hline
\end{tabular}


[Table 1 about here.]

[Figure 1 about here.]

[Figure 2 about here.]

\section{Comparison of recorded data to existing GMPEs}

Equations for the estimation of strong ground motion [e.g. Douglas, 2003] are an important component of both probabilistic and deterministic seismic hazard assessment. As discussed by Douglas et al. [2006] there are no peer-reviewed ground-motion models available based on data from the Lesser Antilles and therefore seismic hazard assessments for this region adopt or adapt GMPEs from seismotectonically-comparable areas. It is important that the validity of the selected GMPEs is tested through a comparison between observed and predicted ground motions from the area of interest. In agreement with the analysis of Douglas et al. [2006], here we use the quantitative and objective method of Scherbaum et al. [2004] for ranking the applicability of existing ground motion estimation equations based on a number of statistical quantities.

Recorded ground motions from the selected subduction earthquakes (see Table 3) have been compared with ground motions estimated by these eight sets of equations: Atkinson and Boore [2003], Crouse [1991], García et al. [2005], Kanno et al. [2006], Lin and Lee [2008], McVerry et al. [2006], Youngs et al. [1997] and Zhao et al. [2006]. Atkinson and Boore [2003] have combined the datasets of Crouse [1991] and Youngs et al. [1997] and also have added much additional data therefore the equations of Atkinson and Boore [2003] could be thought to have superseded the equations of Crouse [1991] and Youngs et al. [1997]. The equations of Crouse [1991] and Youngs et al. [1997] have been included here since they have often been used for seismic hazard assessments of the Antilles and therefore it is important to check their validity. All selected models use moment magnitude. Hypocentral distance has been used as the distance metric for all comparisons since no reliable estimates of the locations of the rupture planes for the considered earthquakes exist. Due to the moderate magnitudes of all earthquakes (except that of 29 th November $2007, M_{w} 7.4$ ) and the large hypocentral distances $(>60 \mathrm{~km})$ the assumption of equality between hypocentral and rupture distance will have only a small effect on the results. Table 2 summarises the GMPEs considered in this study. 
Table 2: Summary of GMPEs considered in this study.

\begin{tabular}{|c|c|c|c|c|c|c|c|c|c|c|c|}
\hline Model & Area & NR & $\mathrm{NE}$ & $\mathrm{M} \min$ & $\mathrm{M} \max$ & $\mathrm{R} \min$ & $\mathrm{R} \max$ & $\mathrm{R}$ metric & Types & Sites & Component \\
\hline Atkinson and Boore [2003] & Worldwide & $1200+$ & $\sim 43$ & 5.5 & 8.3 & $\sim 11$ & $\sim 550$ & $R_{\text {rup }}$ & B, F separate & 4 classes & $\mathrm{C}$ \\
\hline Crouse [1991] & Worldwide & 697 & $?$ & 4.8 & 8.2 & $>8$ & $>866$ & $R_{\text {hypo }}$ & $\mathrm{B}, \mathrm{F}$ together & Only stiff soil & $\mathrm{B}$ \\
\hline García et al. [2005] & Central Mexico & 277 & 16 & 5.2 & 7.4 & $\sim 4$ & $\sim 400$ & $R_{\text {hypo }}$ & B & Only rock & G \\
\hline \multirow[t]{2}{*}{ Kanno et al. [2006] } & Japan+some foreign & $3392+377 \quad$ (shal- & $73+10$ & 5.0 & 8.2 & $\sim 1$ & $\sim 450$ & $R_{\text {rup }}$ & $\mathrm{B}, \mathrm{F}$ together & Uses $V_{s, 30}$ & $\mathrm{R}$ \\
\hline & & low) \& 8150 (deep) & $\& 111$ & & & & & & & & \\
\hline Lin and Lee [2008] & NE Taiwan+some foreign & $4244+139$ & $44+10$ & 4.1 & 8.1 & 15 & 630 & $R_{\text {hypo }}$ & B, F separate & 2 classes & G \\
\hline McVerry et al. [2006] & New Zealand+some foreign & $535+66$ & $49+17$ & 5.1 & 7.4 & 0.1 & 400 & $R_{\text {rup }}$ & B, F separate & 3 classes & $\mathrm{G}$ \\
\hline Youngs et al. [1997] & Worldwide & 476 & 164 & 5.0 & 8.2 & 8.5 & 550.9 & $R_{\text {rup }}$ & B, F separate & 2 classes & G \\
\hline Zhao et al. [2006] & Japan+some foreign & $4518+208$ & $249+20$ & 5.0 & 8.3 & $\sim 0$ & $\sim 300$ & $R_{\text {rup }}$ & B, F separate & 5 classes & G \\
\hline
\end{tabular}

Where Area is the area for which the model was derived, NR is number of records, NE is number of earthquakes, M min and M max are the minimum and maximum magnitudes, R min and

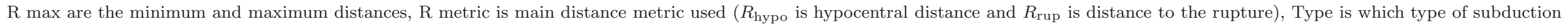
earthquakes are separately modelled (B is intraslab and $\mathrm{F}$ is interface), Sites is which type of sites are considered and Component is the definition of the horizontal component used ( $\mathrm{C}$ is randomly chosen, B is both, $\mathrm{G}$ is geometric mean and $\mathrm{R}$ is resolved). 
The approach of Scherbaum et al. [2004] uses the normalized residuals, i.e. $\epsilon_{i, j}=\left(\log y_{i}-\right.$ $\left.\log y_{i, j}^{\prime}\right) / \sigma_{i, j}$ where $y_{i}$ is the observed $i$ th ground motion value, $y_{i, j}^{\prime}$ is the predicted $i$ th ground motion from the $j$ th model and $\sigma_{i, j}$ is the predicted standard deviation of the $i$ th ground motion from the $j$ th model. The eight selected GMPEs combine the two horizontal ground-motion components in various ways (see Table 2). In this study, predictions from each GMPE have been adjusted, using the empirical factors of Beyer and Bommer [2006, 2007], to give the geometric mean of the two horizontal components (a standard choice in engineering seismology), which has then been compared to the geometric mean of the pairs of observations. Following the method of ranking suggested by Scherbaum et al. [2004] the following goodness-of-fit measures are computed using the normalized residuals: mean (MEANNR), median (MEDNR), standard deviation (STDNR) and median LH (MEDLH), where the LH of a value $z_{0}$ is defined by: $\operatorname{LH}\left(\left|z_{0}\right|\right)=\operatorname{Erf}\left(\left|z_{0}\right| / \sqrt{2}\right.$, inf $)$ where $\operatorname{Erf}(z)$ is the error function $\frac{2}{\sqrt{\pi}} \int_{0}^{z} \exp \left(-t^{2}\right) \mathrm{d} t$.

The same ranking criteria as used by Scherbaum et al. [2004] have been used here (Table 4). The goodness-of-fit measures are computed using PGA and spectral accelerations at 12 standard periods, roughly logarithmically spaced, between 0.05 and $2 \mathrm{~s}$ (selected in order to exclude long-period spectral ordinates that could be affected by recording noise). In contrast to Douglas et al. [2006] who used all the periods for which coefficients for a GMPE were available, a common set of periods was used here to give an equal weighting, with respect to models, to the match between observations and predictions for the entire period range of interest. For example, if one model provides many coefficients for short periods, where the match between the predictions and observations is good, but fewer at longer periods, where the match is poorer, then this model could be ranked higher than another model with coefficients for more equally spaced spectral periods. The results for the eight selected models are given in Table 5 for all subduction events combined and in Tables 6 and 7 for intraslab and interface earthquakes considered separately.

[Table 2 about here.]

[Table 3 about here.]

[Table 4 about here.]

[Table 5 about here.]

The results show that most of the tested GMPEs do a poor job of predicting the observed ground motions and their variabilities in the Lesser Antilles. Five [Atkinson and Boore, 2003, Crouse, 1991, García et al., 2005, Lin and Lee, 2008, McVerry et al., 2006] out of the eight selected models are ranked in the lowest capability class (D) by the method of Scherbaum 
et al. [2004] and only one model, that of Kanno et al. [2006], is ranked higher than C. The results for the GMPEs of Atkinson and Boore [2003], Crouse [1991] and Youngs et al. [1997] are in agreement with those presented by Douglas et al. [2006] based on their smaller dataset. Considering the records from intraslab or interface events separately does not significantly affect the results obtained (although Kanno et al. [2006] performs better for ground motions from intraslab events than for interface events). Figure 3 shows the normalized residuals for PGA and for spectral acceleration (SA) at 1s for the equation of Kanno et al. [2006] with respect to hypocentral distance and $M_{w}$ for the two types of subduction earthquakes (intraslab and interface). It shows that the model of Kanno et al. [2006] generally provides good predictions of PGA and SA at $1 \mathrm{~s}$ at all distances from 50 to $300 \mathrm{~km}$ and for all magnitudes from 4.8 to 7.4 for both types of events.

[Figure 3 about here.]

In general, most of the selected models overpredict ground motions in the Lesser Antilles (signified by negative values of MEDNR and MEANNR) to varying degrees. In contrast, and in agreement with the results of Douglas et al. [2006], the model of Atkinson and Boore [2003] greatly underpredicts ground motions. All the selected models underestimate the groundmotion variability observed in the Lesser Antilles (shown by values of STDNR greater than unity) although for the models of Kanno et al. [2006] and Youngs et al. [1997] this underestimation of the variability is small (in fact, these models predict larger variabilities for intraslab events than observed). As discussed by Douglas et al. [2006] the reasons for the apparently poor match between predictions and observations could be partly due to an observational dataset from a different magnitude and distance range than used by the developers of the selected GMPEs. It has been observed [e.g. Bommer et al., 2007] that ground motions from small earthquakes have larger variability and scale differently with magnitude and distance than motions from moderate and large events. Fukushima et al. [2003, Appendix A], using an $\omega^{2}$ source model, give a theoretical justification for different magnitude scaling of ground motions from moderate and large earthquakes. The larger variability in observations from the Lesser Antilles could be partly explained by poor site classification of the strong-motion stations, due to a lack of knowledge, or site effects that are poorly modelled by the site classifications used by the selected GMPEs. Finally, the effect of regional dependence of strong ground motions [e.g. Douglas, 2007] could possibly contribute to the differences between predictions and observations. However, as shown by Douglas [2007] regional dependence of ground motions is difficult to clearly demonstrate due to limitations in observational datasets. 


\section{Conclusions}

This brief article has sought to update the analysis of Douglas et al. [2006] in quantitatively comparing the observed and predicted ground motions recorded on islands in the Lesser Antilles (mainly Guadeloupe and Martinique) from subduction earthquakes. It was decided to update the analysis of Douglas et al. [2006] for this type of earthquake for a number of reasons: a) the number of available strong-motion records from subduction earthquakes from this region is about double that available when Douglas et al. [2006] compiled data from this region; b) many records from a large $\left(M_{w} 7.4\right)$ intraslab earthquakes that occurred in 2007 improved the distribution with respect to magnitude and distance; and c) a number of new GMPEs for subduction earthquakes have been published and hence can be compared to the observations.

One of the most important findings is that the recent ground-motion models developed from Japanese data [Kanno et al., 2006, Zhao et al., 2006] provide quite good predictions of observed earthquake ground motions and their variabilities in the Lesser Antilles. Other recent GMPEs derived for Mexico [García et al., 2005], Taiwan [Lin and Lee, 2008] and New Zealand [McVerry et al., 2006] are ranked poorly by the method of Scherbaum et al. [2004] for this dataset. Kanno et al. [2006] note that, in contrast to Japan (their zone of interest), Taiwan is located on a much-fractured continental margin; this could partly explain why the model of Lin and Lee [2008], in contrast to those from Japan, poorly predicts ground motions in the Lesser Antilles. This study has confirmed the findings of Douglas et al. [2006] with respect to the three ground-motion models derived using data from various subduction zones combined into a single dataset [Atkinson and Boore, 2003, Crouse, 1991, Youngs et al., 1997]. Namely that the models of Atkinson and Boore [2003] and Crouse [1991] poorly predict the observed ground motions and significantly underestimate ground-motion variability but that the GMPEs of Youngs et al. [1997] provide reasonable predictions of the median ground motions and their variabilities. Considering the intraslab and interface data separately when applying the method of Scherbaum et al. [2004] does not lead to greatly different results. All of these results, however, are based on comparisons between ground motions from magnitudes and distance ranges generally outside those used to derive the tested GMPEs; observations generally come from moderate magnitudes and great distances whereas the GMPEs have been derived for larger events at shorter distances.

The main implication of this analysis for seismic hazard assessments in the Lesser Antilles is that, due to the generally poor fit between observations and predictions from the available models for subduction events, it is vital that any seismic hazard assessment for this region selects a number of GMPEs so that the epistemic uncertainty in ground-motion prediction is not underestimated. The ranking of the different models presented here could be useful as one 
component of a scheme to weight the predictions from the various GMPEs. In addition, due to the large quantity of high-quality strong-motion data available from the Lesser Antilles we suggest that these data be integrated into datasets for the derivation of new GMPEs for the prediction of earthquake shaking from subduction events.

\section{Acknowledgements}

This study was funded by research and public service BRGM projects. The strong-motion networks on Guadeloupe are operated by BRGM and the Institut de Physique du Globe de Paris (IPGP), which is under the aegis of the Réseau Accélérometrique Permanent (RAP) of France. The strong-motion networks on Martinique are operated by BRGM, Conseil Général de la Martinique and IPGP for the RAP. The RAP data centre is based at Laboratoire de Géophysique Interne et de Tectonophysique, Grenoble. The strong-motion network on Trinidad and the instrument on Dominica are operated by the Seismic Research Center, University of West Indies. We are very grateful to all staff at the Seismic Research Center, especially technical staff members Nisha Nath and Lutchman Pollard. Data from the Bouillante broadband stations were provided by Philippe Jousset (BRGM). We are very grateful to the personnel of these organisations for operating the stations and providing us with the data, without which this study would have been impossible. Figure 1 was kindly created by Philippe Jousset using GMT [Wessel and Smith, 1991]. Didier Bertil (BRGM) provided some useful advice on this study. Finally, we thank one anonymous reviewer and Yoshimitsu Fukushima for their useful reviews of an earlier version of this article.

\section{References}

G. M. Atkinson and D. M. Boore. Empirical ground-motion relations for subduction zone earthquakes and their application to Cascadia and other regions. Bulletin of the Seismological Society of America, 93(4):1703-1729, 2003.

M. Bengoubou-Valerius, S. Bazin, D. Bertil, F. Beauducel, and A. Bosson. CDSA: A new seismological data center for the French Lesser Antilles. Seismological Research Letters, 79 (1):90-102, Jan-Feb 2008.

K. Beyer and J. J. Bommer. Erratum: Relationships between median values and between aleatory variabilities for different definitions of the horizontal component of motion. Bulletin of the Seismological Society of America, 97(5):1769, Oct 2007. doi: 10.1785/0120070128. 
K. Beyer and J. J. Bommer. Relationships between median values and between aleatory variabilities for different definitions of the horizontal component of motion. Bulletin of the Seismological Society of America, 96(4A):1512-1522, Aug 2006. doi: 10.1785/0120050210.

J. J. Bommer, P. J. Stafford, J. E. Alarcón, and S. Akkar. The influence of magnitude range on empirical ground-motion prediction. Bulletin of the Seismological Society of America, 97 (6):2152-2170, 2007. doi: 10.1785/0120070081.

C. B. Crouse. Ground-motion attenuation equations for earthquakes on the Cascadia subduction zones. Earthquake Spectra, 7(2):201-236, 1991.

J. Douglas. Earthquake ground motion estimation using strong-motion records: A review of equations for the estimation of peak ground acceleration and response spectral ordinates. Earth-Science Reviews, 61(1-2):43-104, 2003.

J. Douglas. On the regional dependence of earthquake response spectra. ISET Journal of Earthquake Technology, 44(1):71-99, Mar 2007.

J. Douglas, D. Bertil, A. Roullé, P. Dominique, and P. Jousset. A preliminary investigation of strong-motion data from the French Antilles. Journal of Seismology, 10(3):271-299, 2006. doi: $10.1007 / \mathrm{s} 10950-006-9016-0$.

Y. Fukushima, C. Berge-Thierry, P. Volant, D.-A. Griot-Pommera, and F. Cotton. Attenuation relation for western Eurasia determined with recent near-fault records from California, Japan and Turkey. Journal of Earthquake Engineering, 7(4):573-598, 2003.

D. García, S. K. Singh, M. Herráiz, M. Ordaz, and J. F. Pacheco. Inslab earthquakes of central Mexico: Peak ground-motion parameters and response spectra. Bulletin of the Seismological Society of America, 95(6):2272-2282, Dec 2005. doi: 10.1785/0120050072.

T. Kanno, A. Narita, N. Morikawa, H. Fujiwara, and Y. Fukushima. A new attenuation relation for strong ground motion in Japan based on recorded data. Bulletin of the Seismological Society of America, 96(3):879-897, 2006. doi: 10.1785/0120050138.

P.-S. Lin and C.-T. Lee. Ground-motion attenuation relationships for subduction-zone earthquakes in northeastern Taiwan. Bulletin of the Seismological Society of America, 98(1): 220-240, Feb 2008. doi: 10.1785/0120060002.

G. H. McVerry, J. X. Zhao, N. A. Abrahamson, and P. G. Somerville. New Zealand acceleration response spectrum attenuation relations for crustal and subduction zone earthquakes. Bulletin of the New Zealand Society for Earthquake Engineering, 39(4):1-58, Mar 2006. 
F. Scherbaum, F. Cotton, and P. Smit. On the use of response spectral-reference data for the selection and ranking of ground-motion models for seismic-hazard analysis in regions of moderate seismicity: The case of rock motion. Bulletin of the Seismological Society of America, 94(6):2164-2185, Dec 2004. doi: 10.1785/0120030147.

A. Schlupp, C. Sira, M. Cara, S. Bazin, C. Michel, J. Régnier, C. Beauval, N. Feuillet, J.-B. De Chabalier, A.-V. Barras, S. Auclair, M.-P. Bouin, C. Duclos, and M. Granet. Séisme de Martinique du 29 novembre 2007. Synthèse sismologique et étude macrosismique BCSF2008R1, Bureau Central Sismologique Français, 2008. 132 p., 266 figures, 3 tables, 5 annexes. In French.

J. P. Stewart. Variations between foundation-level and free-field earthquake ground motions. Earthquake Spectra, 16(2):511-532, May 2000.

P. Wessel and W. H. F. Smith. Free software helps map and display data. EOS Transactions $A G U, 72: 441,1991$.

R. R. Youngs, S.-J. Chiou, W. J. Silva, and J. R. Humphrey. Strong ground motion attenuation relationships for subduction zone earthquakes. Seismological Research Letters, 68(1):58-73, Jan/Feb 1997.

J. X. Zhao, J. Zhang, A. Asano, Y. Ohno, T. Oouchi, T. Takahashi, H. Ogawa, K. Irikura, H. K. Thio, P. G. Somerville, Y. Fukushima, and Y. Fukushima. Attenuation relations of strong ground motion in Japan using site classification based on predominant period. Bulletin of the Seismological Society of America, 96(3):898-913, 2006. doi: 10.1785/0120050122. 


\section{List of Figures}

1 Map showing the locations, focal mechanisms and magnitudes of those earthquakes whose data have been used for this study. Also shown are the locations (small triangles) of the strong-motion stations that have operated, or are still operating, on Guadeloupe, Martinique, Trinidad and Dominica and the five broadband stations at Bouillante. . . . . . . . . . . . . . . . . . . .

2 Distribution in terms of magnitude, hypocentral distance and focal depth of the data recorded on Guadeloupe, Martinique, Trinidad and Dominica of the selected intraslab and interface earthquakes. All earthquakes have a moment magnitude given by Global CMT. The number of records within each focal depth class is given in the legend. . . . . . . . . . . . . . . . . . 16

3 Normalized residuals for the equation of Kanno et al. [2006] with respect to hypocentral distance and $M_{w}$. Dots and crosses are for intraslab and interface events respectively. . . . . . . . . . . . . . . . . 


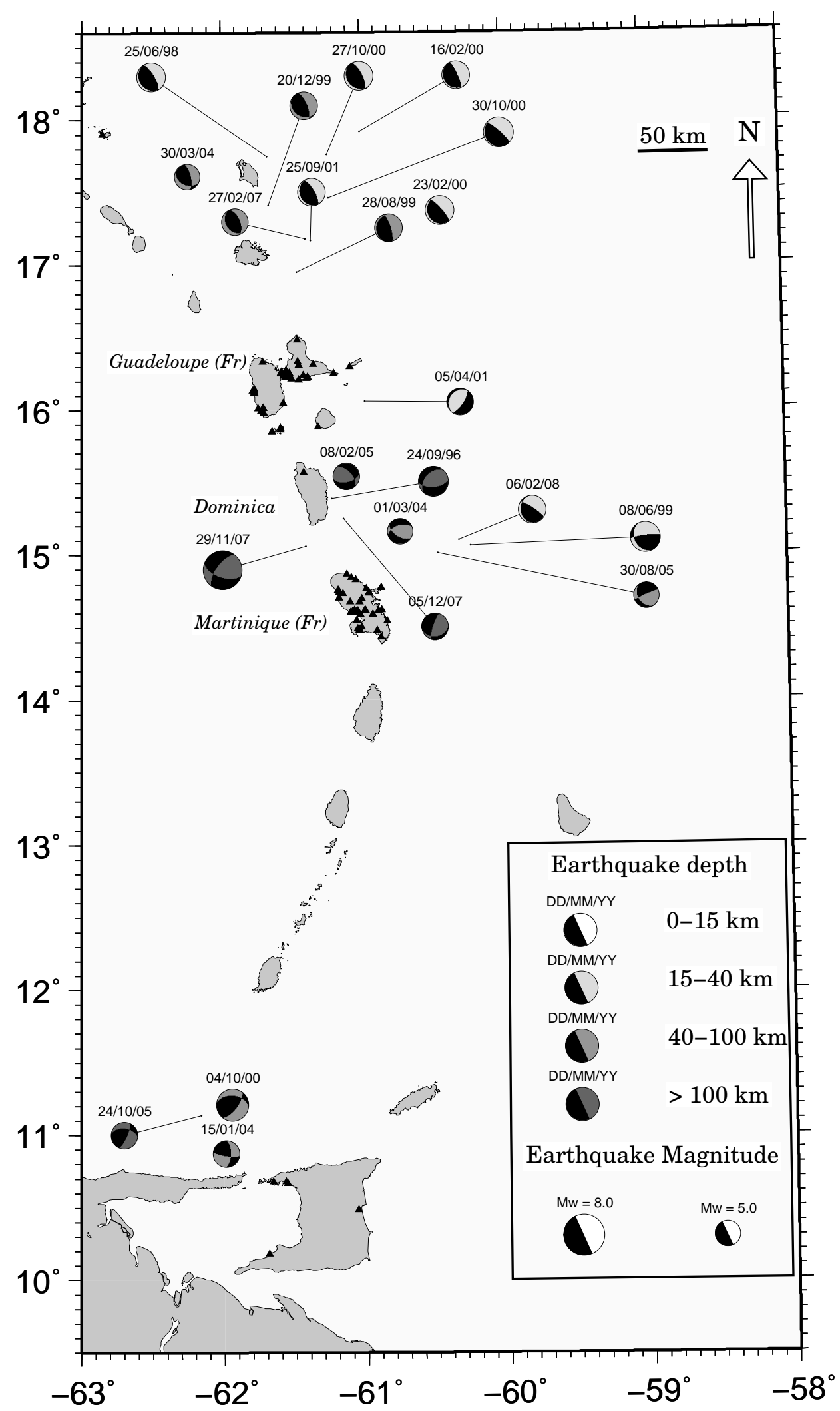

Figure 1: Map showing the locations, focal mechanisms and magnitudes of those earthquakes whose data have been used for this study. Also shown are the locations (small triangles) of the strong-motion stations that have operated, or are still operating, on Guadeloupe, Martinique, Trinidad and Dominica and the five broadband stations at Bouillante. 


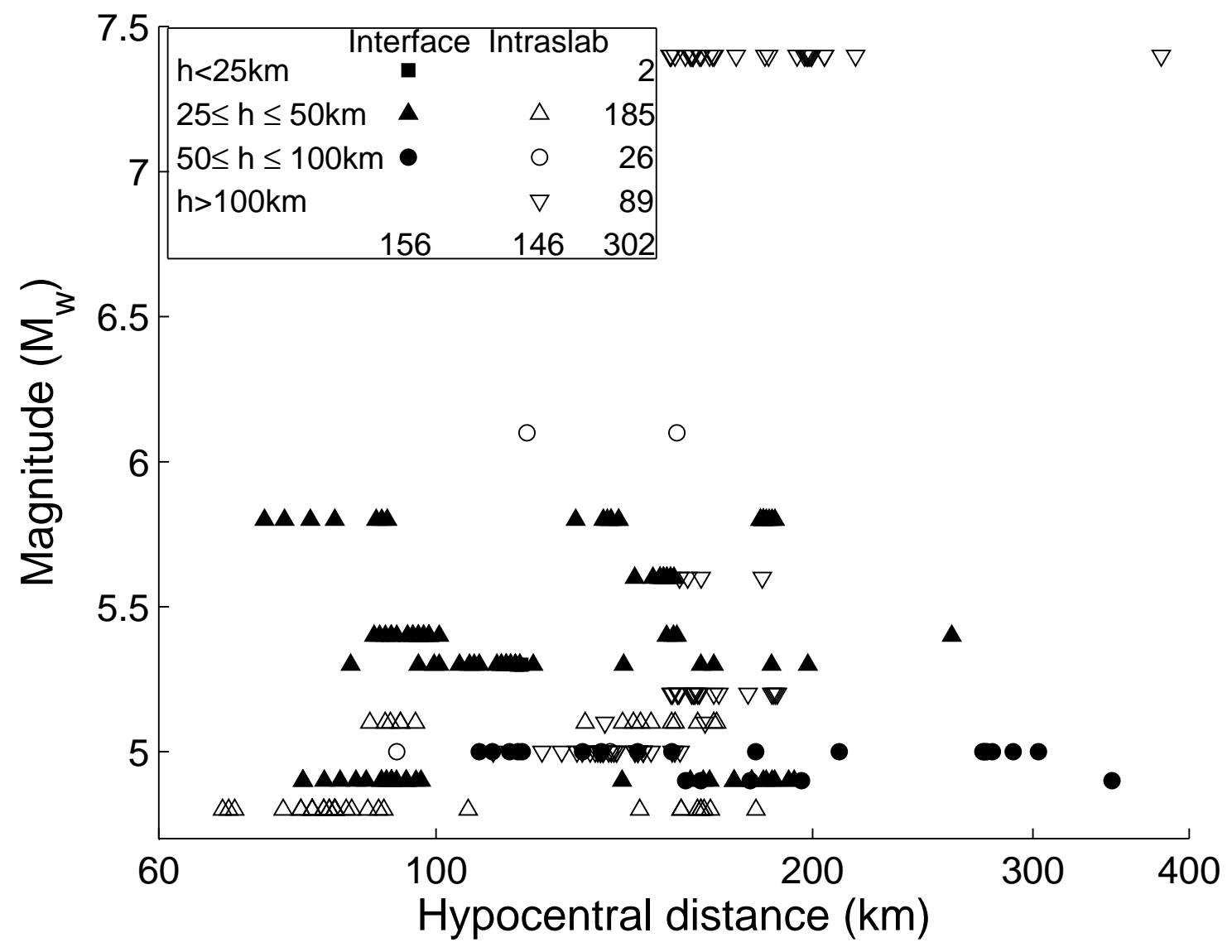

Figure 2: Distribution in terms of magnitude, hypocentral distance and focal depth of the data recorded on Guadeloupe, Martinique, Trinidad and Dominica of the selected intraslab and interface earthquakes. All earthquakes have a moment magnitude given by Global CMT. The number of records within each focal depth class is given in the legend. 

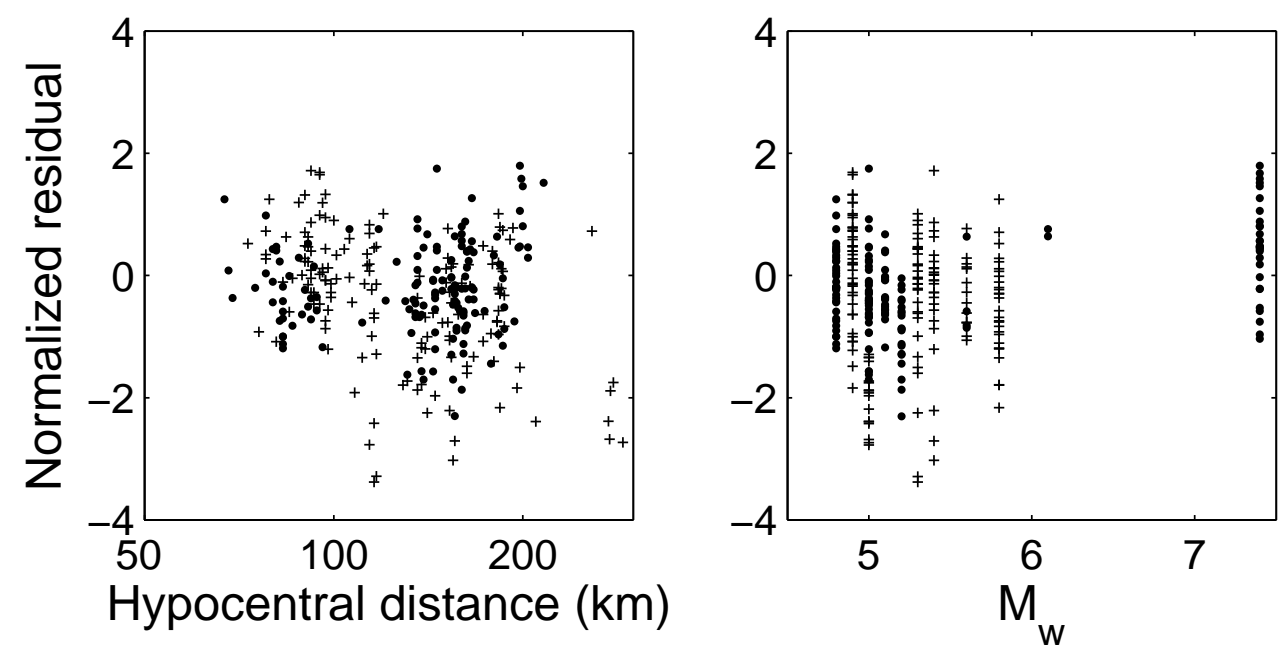

a) For PGA
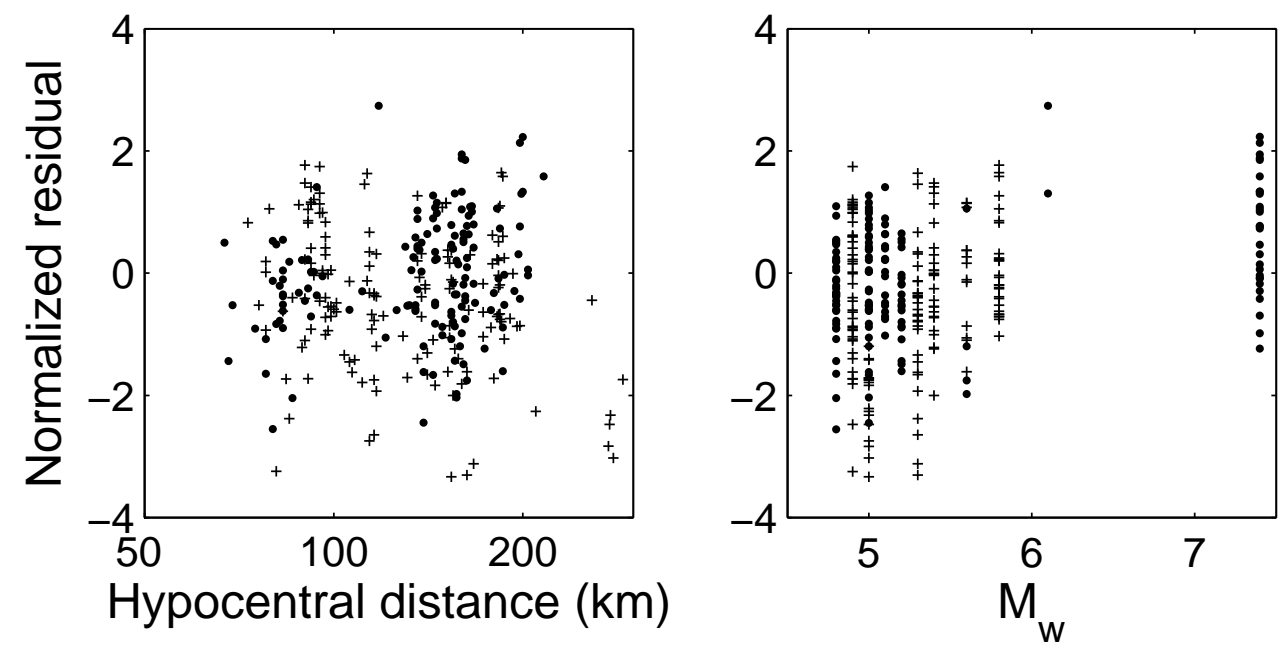

b) For spectral acceleration at $1 \mathrm{~s}$

Figure 3: Normalized residuals for the equation of Kanno et al. [2006] with respect to hypocentral distance and $M_{w}$. Dots and crosses are for intraslab and interface events respectively. 


\section{List of Tables}

1 Information on strong-motion stations that have operated, or are still operating, on Trinidad and Dominica and whose data has been used in this article. All these stations belong to the Seismic Research Center (SRC) of the University of West Indies. $\mathrm{R}$ is rock and $\mathrm{S}$ is soft soil (in this case reclaimed land). . . . . . . . . 5

2 Summary of GMPEs considered in this study. . . . . . . . . . . . . . . . . 7

3 Intraslab and interface earthquakes with $M_{w}$ estimates from the Global Centroid Moment Tensor catalogue recorded by strong-motion networks on Guadeloupe, Martinique, Trinidad or Dominica. . . . . . . . . . . . . . . 19

4 Criteria defining capability classes of Scherbaum et al. [2004]. . . . . . . . . 20

$5 \quad$ Ranking of different GMPEs for modelling the entire Lesser Antilles subduction earthquake ground motion dataset. MEDLH is the median LH value (see text), MEDNR is the median normalized residual, MEANNR is the mean normalized residual and STDNR is the standard deviation of the normalized residuals. . .

6 Ranking of different GMPEs for modelling the Lesser Antilles intraslab earthquake ground motion dataset. MEDLH is the median LH value (see text), MEDNR is the median normalized residual, MEANNR is the mean normalized residual and STDNR is the standard deviation of the normalized residuals. . .

7 Ranking of different GMPEs for modelling the Lesser Antilles interface earthquake ground motion dataset. MEDLH is the median LH value (see text), MEDNR is the median normalized residual, MEANNR is the mean normalized residual and STDNR is the standard deviation of the normalized residuals. . . 
Table 3: Intraslab and interface earthquakes with $M_{w}$ estimates from the Global Centroid Moment Tensor catalogue recorded by strong-motion networks on Guadeloupe, Martinique, Trinidad or Dominica.

\begin{tabular}{|c|c|c|c|c|c|c|c|}
\hline $\begin{array}{l}\text { Date } \\
\text { DD/MM/YYYY }\end{array}$ & $\begin{array}{l}\text { Time } \\
\text { (UTC) }\end{array}$ & $M_{w}$ & $\begin{array}{r}\text { Depth } \\
(\mathrm{km}) \\
\end{array}$ & Type & $\begin{array}{r}\text { Number of } \\
\text { records } \\
\end{array}$ & $\begin{array}{r}R_{\text {hypo }} \text { range } \\
(\mathrm{km})\end{array}$ & $\begin{array}{r}\text { PGA range } \\
\left(\mathrm{m} / \mathrm{s}^{2}\right) \\
\end{array}$ \\
\hline $24 / 09 / 1996$ & $11: 42$ & 5.6 & 139 & Intraslab & 4 & $157-182$ & $0.05-0.08$ \\
\hline $25 / 06 / 1998$ & 21:03 & 5.6 & 30 & Interface & 4 & $149-154$ & $0.02-0.03$ \\
\hline 08/06/1999 & 12:04 & 5.8 & 31 & Interface & 19 & $73-187$ & $0.01-1.28$ \\
\hline 28/08/1999 & 04:27 & 5.4 & 30 & Interface & 16 & $89-101$ & $0.03-0.13$ \\
\hline 20/12/1999 & 10:43 & 5.3 & 29 & Interface & 15 & $112-120$ & $0.03-0.16$ \\
\hline $16 / 02 / 2000$ & 07:03 & 5.3 & $0^{*}$ & Interface & 2 & $116-117$ & 0.004-0.004 \\
\hline $23 / 02 / 2000$ & 19:20 & 5.4 & 34 & Interface & 3 & $153-156$ & $0.01-0.01$ \\
\hline $04 / 10 / 2000$ & 14:37 & 6.2 & 93 & Intraslab & 2 & $118-156$ & $0.21-0.66$ \\
\hline $27 / 10 / 2000$ & 19:02 & 5.6 & 30 & Interface & 9 & $144-155$ & $0.02-0.10$ \\
\hline $30 / 10 / 2000$ & 03:07 & 5.8 & 33 & Interface & 9 & $129-140$ & $0.03-0.19$ \\
\hline $05 / 04 / 2001$ & $13: 54$ & 5.1 & 47 & Intraslab & 17 & 89-168 & $0.02-0.20$ \\
\hline $25 / 09 / 2001$ & $23: 16$ & 5.4 & 27 & Interface & 6 & $90-258$ & $0.02-0.42$ \\
\hline $15 / 01 / 2004$ & 10:56 & 5.0 & 83 & Intraslab & 2 & $93-138$ & $0.01-0.14$ \\
\hline 01/03/2004 & 06:12 & 4.8 & 43 & Intraslab & 36 & $67-180$ & $0.01-0.88$ \\
\hline $30 / 03 / 2004$ & 16:23 & 4.9 & 70 & Interface & 5 & $158-347$ & $0.002-0.02$ \\
\hline 08/02/2005 & 02:18 & 5.0 & 102 & Intraslab & 34 & $111-157$ & $0.01-0.37$ \\
\hline $30 / 08 / 2005$ & 14:02 & 4.9 & 49 & Interface & 38 & 78-193 & $0.02-0.81$ \\
\hline $24 / 10 / 2005$ & 09:19 & 5.1 & 114 & Intraslab & 2 & $136-164$ & $0.03-0.08$ \\
\hline $27 / 02 / 2007$ & 09:42 & 5.0 & 50 & Interface & 17 & $108-303$ & $0.001-0.04$ \\
\hline $29 / 11 / 2007$ & 19:00 & 7.4 & 148 & Intraslab & 29 & $154-380$ & $0.09-1.66$ \\
\hline $05 / 12 / 2007$ & $12: 11$ & 5.2 & 144 & Intraslab & 20 & $154-187$ & $0.01-0.07$ \\
\hline $06 / 02 / 2008$ & 18:38 & 5.3 & 30 & Interface & 13 & 85-198 & $0.004-0.13$ \\
\hline 13 events & & $4.9-5.8$ & $0-70$ & Interface & 156 & $73-347$ & $0.001-1.28$ \\
\hline 9 events & & $4.8-7.4$ & $43-148$ & Intraslab & 146 & $67-380$ & $0.004-1.66$ \\
\hline
\end{tabular}

$M_{w}$ estimates have been taken from the Global CMT catalogue and times and locations from the CDSA, IPGP or SRC catalogues (or NEIC catalogue for events not relocated by these agencies). * indicates that the focal depth was constrained within the localization procedure. Only data from ground response instruments are listed here. One record refers to three mutually perpendicular components. Earthquakes have been classified as intraslab or interface events by their horizontal location, focal depth and faulting mechanism. 
Table 4: Criteria defining capability classes of Scherbaum et al. [2004].

\begin{tabular}{lllll}
\hline $\begin{array}{l}\text { Capability } \\
\text { class }\end{array}$ & MEDLH & $\begin{array}{l}\text { Absolute value } \\
\text { of MEANNR }\end{array}$ & $\begin{array}{l}\text { Absolute value } \\
\text { of MEDNR }\end{array}$ & STDNR \\
\hline $\mathrm{A}$ & $\geq 0.4$ & $<0.25$ & $<0.25$ & $<1.125$ \\
$\mathrm{~B}$ & $\geq 0.3$ & $<0.5$ & $<0.5$ & $<1.25$ \\
$\mathrm{C}$ & $\geq 0.2$ & $<0.75$ & $<0.75$ & $<1.5$ \\
$\mathrm{D}$ & \multicolumn{5}{r}{ Does not fulfill the criteria for class A, B or C } \\
\hline
\end{tabular}


Table 5: Ranking of different GMPEs for modelling the entire Lesser Antilles subduction earthquake ground motion dataset. MEDLH is the median LH value (see text), MEDNR is the median normalized residual, MEANNR is the mean normalized residual and STDNR is the standard deviation of the normalized residuals.

\begin{tabular}{lcrrrr}
\hline Model & Rank & MEDLH & MEDNR & MEANNR & STDNR \\
\hline Atkinson and Boore [2003] & $\mathrm{D}$ & 0.001 & 2.413 & 2.532 & 2.429 \\
Crouse [1991] & $\mathrm{D}$ & 0.008 & -1.986 & -1.784 & 2.069 \\
García et al. [2005] & \multicolumn{5}{c}{ N/A - model only for intraslab events } \\
Kanno et al. [2006] & B & $\mathbf{0 . 3 5 1}$ & $\mathbf{- 0 . 2 5 4}$ & $\mathbf{- 0 . 2 8 0}$ & $\mathbf{1 . 0 0 4}$ \\
Lin and Lee [2008] & $\mathrm{D}$ & 0.140 & -0.507 & -0.547 & 1.503 \\
McVerry et al. [2006] & $\mathrm{D}$ & 0.049 & -0.968 & -1.048 & 1.800 \\
Youngs et al. [1997] & $\mathrm{C}$ & 0.241 & -0.711 & -0.707 & 1.061 \\
Zhao et al. [2006] & $\mathrm{C}$ & 0.238 & -0.432 & -0.479 & 1.201 \\
\hline
\end{tabular}


Table 6: Ranking of different GMPEs for modelling the Lesser Antilles intraslab earthquake ground motion dataset. MEDLH is the median LH value (see text), MEDNR is the median normalized residual, MEANNR is the mean normalized residual and STDNR is the standard deviation of the normalized residuals.

\begin{tabular}{lcrrrr}
\hline Model & Rank & MEDLH & MEDNR & MEANNR & STDNR \\
\hline Atkinson and Boore [2003] & $\mathrm{D}$ & 0.039 & 1.368 & 1.165 & 1.810 \\
Crouse [1991] & $\mathrm{D}$ & 0.011 & -2.054 & -1.888 & 1.803 \\
García et al. [2005] & $\mathrm{D}$ & 0.104 & -0.191 & -0.472 & 1.678 \\
Kanno et al. [2006] & $\mathrm{A}$ & $\mathbf{0 . 4 2 5}$ & $\mathbf{- 0 . 1 9 9}$ & $\mathbf{- 0 . 1 5 1}$ & $\mathbf{0 . 8 7 8}$ \\
Lin and Lee [2008] & $\mathrm{D}$ & 0.178 & -0.586 & -0.649 & 1.319 \\
McVerry et al. [2006] & $\mathrm{D}$ & 0.025 & -1.546 & -1.630 & 1.686 \\
Youngs et al. [1997] & $\mathrm{D}$ & 0.238 & -0.825 & -0.853 & 0.956 \\
Zhao et al. [2006] & $\mathrm{C}$ & 0.249 & -0.593 & -0.640 & 1.088 \\
\hline
\end{tabular}


Table 7: Ranking of different GMPEs for modelling the Lesser Antilles interface earthquake ground motion dataset. MEDLH is the median LH value (see text), MEDNR is the median normalized residual, MEANNR is the mean normalized residual and STDNR is the standard deviation of the normalized residuals.

\begin{tabular}{lcrrrr}
\hline Model & Rank & MEDLH & MEDNR & MEANNR & STDNR \\
\hline Atkinson and Boore [2003] & $\mathrm{D}$ & 0.000 & 3.406 & 3.812 & 2.229 \\
Crouse [1991] & $\mathrm{D}$ & 0.005 & -1.839 & -1.647 & 2.371 \\
García et al. [2005] & \multicolumn{5}{c}{ N/A - model only for intraslab events } \\
Kanno et al. [2006] & $\mathrm{C}$ & 0.294 & -0.319 & -0.401 & 1.110 \\
Lin and Lee [2008] & $\mathrm{D}$ & 0.112 & -0.410 & -0.452 & 1.652 \\
McVerry et al. [2006] & $\mathrm{D}$ & 0.091 & -0.470 & -0.503 & 1.731 \\
Youngs et al. [1997] & $\mathrm{C}$ & 0.243 & -0.578 & -0.569 & 1.134 \\
Zhao et al. [2006] & $\mathrm{C}$ & 0.229 & -0.275 & -0.328 & 1.280 \\
\hline
\end{tabular}

